\title{
Avaliação Microbiológica, Detecção e Susceptibilidade Aos Antimicrobianos de Potenciais Enteropatógenos Das Famílias Enterobacteriaceae e Vibrionaceae em Mexilhões Perna Perna Coletados Na Praia de Itaipu, Niterói-RJ
}

Marcelly Miranda Aybal Jayme (I), Jorge Gonçalo Caldeira Nunes de Matos (I), Alessandro Sales (II), Mônica Conceição NunesCarvalho (III), Mara Lucia Penna Queiroz (I), Angela Correa de Freitas-Almeida (I), Fábio Vieira Araujo (II)

(I) UERJ/FCM/DIMI - Universidade do Estado do Rio de Janeiro (Av. Boulevard Vinte e Oito de Setembro, 87 fundos 3o. andar. CEP: 20551-030), (II) FFP/UERJ - Universidade do Estado do Rio de Janeiro (São Gonçalo), (III) IQ/UFRJ - Universidade Federal do Rio de Janeiro (Ilha do Fundão)

\section{Resumo}

Por serem organismos filtradores, os mexilhões devem ser extraídos para consumo humano somente de águas com padrões microbiológicos regulamentados pelo Conselho Nacional do Meio Ambiente, uma vez que intoxicações alimentares de origem bacteriana são as consequências mais comuns relacionadas ao consumo destes moluscos. Após a retirada dos costões, estes são aferventados para retirada das valvas, lavados, acondicionados em sacos plásticos e transportados até o mercado onde são comercializados. Com objetivo de avaliar a qualidade microbiológica de mexilhões Perna perna coletados na praia de Itaipu, Niterói - RJ em condições in natura, após aferventados e comercializados no Mercado São Pedro, referência no comércio de pescado no Rio de Janeiro, foram realizadas a estimativa de coliformes totais e termotolerantes e pesquisa de Escherichia coli, Salmonella spp. e Vibrio spp. por metodologia convencional e molecular, bem como seus perfis de resistência a antimicrobianos. Do total de amostras analisadas $(\mathrm{n}=27)$ apenas 3 dos

\footnotetext{
Referência:

Marcelly Miranda Aybal Jayme, Jorge Gonçalo Caldeira Nunes de Matos, Alessandro Sales, Mônica Conceição NunesCarvalho, Mara Lucia Penna Queiroz, Angela Correa de Freitas-Almeida, Fábio Vieira Araujo.Avaliação Microbiológica, Detecção e Susceptibilidade Aos Antimicrobianos de Potenciais Enteropatógenos Das Famílias Enterobacteriaceae e Vibrionaceae em Mexilhões Perna Perna Coletados Na Praia de Itaipu, Niterói-Rj. In: Anais do 12 Congresso Latinoamericano de Microbiologia e Higiene de Alimentos - MICROAL 2014 [= Blucher Food Science Proceedings, num.1, vol.1]. São Paulo: Editora Blucher, 2014. DOI 10.5151/foodsci-microal-185
} 
mexilhões in natura, 3 dos aferventados e 1 do comercializado se encontravam dentro dos padrões aceitáveis pela legislação vigente. Não houve diferença significativa entre as contagens de coliformes termotolerantes nos mexilhões analisados sob estas diferentes condições, mas sim entre os coletados nos períodos seco e chuvoso. Somente uma das nove coletas de água mostrou-se própria para o cultivo de mexilhões (até $14 \mathrm{CF} / 100 \mathrm{~mL}$ ). Foram isoladas e caracterizadas fisiologicamente 77 cepas de E. coli e confirmadas por PCR nos sorotipos EPEC, STEC e EAEC. Foram caracterizadas molecularmente uma cepa de Salmonella spp., 46 de Vibrio spp. e as espécies V. cholerae $(n=2), V$. vulnificus $(n=1), V$. parahaemolyticus $(n=1)$ e V. mimicus $(n=1)$. Entre as cepas de E. coli e Vibrio spp., 13 e 68,6\% apresentaram multirresistência (resistência a 3 classes de antimicrobianos) e 15,6 e 72,5\% apresentaram resistência múltipla, respectivamente. A cepa de Salmonella spp. foi susceptível a todos os antimicrobianos testados. Foi possível detectar todos os genes pesquisados para as espécies e sorotipos estudados direto do caldo de enriquecimento, com exceção dos sorotipos de Salmonella e a espécie V. cholerae. Considerando os resultados do presente trabalho, pode-se inferir que os mexilhões, amplamente comercializados nos municípios de Niterói e Rio de Janeiro, podem se constituir em risco para a saúde pública, necessitando dos órgãos competentes uma eficiente fiscalização nos pontos de venda e cultivo destes moluscos.

Palavras-Chave: Mexilhão, E. coli, Salmonella spp., Vibrio spp., Antimicrobianos

Agência de Fomento: FAPERJ 